\title{
O aluno da Educação de Jovens e Adultos (EJA) na visão de jornalistas e de um livro didático ${ }^{1}$
}

\author{
Evelise Raquel Morari* \\ Claudete Moreno Ghiraldelo**
}

\begin{abstract}
Resumo
O objetivo deste artigo é identificar e analisar as representações (imaginárias) do aluno da EJA, construídas pela autora do livro didático de Língua Portuguesa, Por uma vida melhor, dirigido a esse público, e por nove artigos jornalísticos sobre o livro. Os jornalistas referiram-se ao livro como "livro contendo erros", por ele incluir o tema "variação linguística", conteúdo previsto pelos Parâmetros Curriculares Nacionais. Por meio desse material (livro e artigos jornalísticos), foi possível detectar as representações do aluno da EJA, que é de escola pública e de baixa renda. Esta pesquisa se baseia nos pressupostos teóricos da Análise de Discurso francesa.

Palavras-chave: Representações (imaginárias) aluno EJA; Língua Portuguesa para EJA; Ensino Fundamental (2º Ciclo) - EJA; Análise do Discurso francesa; Linguística Aplicada.
\end{abstract}

\section{Analysis of journalists and textbook viewpoint for Adults and Youth Education students}

\begin{abstract}
This article intends to identify and analyse the (imaginary) representations of student of The Adults and Youth Education (EJA, in Portuguese) that are constructed by the author of textbook Por uma vida melhor, and by journalists at nine newspaper article reported. The journalists write about a supposed book "containing mistakes", because it includes a part of linguistic variation, expected content by National Curricular Parameters (PCN, in Portuguese). Through this material (textbook and newspaper article reported), there was detected the representations of EJA's student. This student is low-income and from public school. The research is based upon a French Discourse Analysis.

Keywords: (Imaginary) Representations of student of Adults and Youth Education; Portuguese Language for Adults and Youth Education; Elementary Education (Second Cycle) - Adults and Youth Education; French Discourse Analysis; Applied Linguistics.
\end{abstract}

\section{Introdução}

Em meados de 2011, o Brasil viveu um grande "alvoroço midiático" em torno do livro didático multidisciplinar, Por uma vida melhor, dirigido a alunos da Educação de Jovens e Adultos (EJA), do $2^{\circ}$ Ciclo do Ensino Fundamental, que equivale ao período do $6^{\circ}$ ao $9^{\circ}$ ano do Ensino Fundamental regular. Adquirido pelo Programa Nacional do Livro Didático (PNLD) durante o primeiro mandato da Presidente da República Dilma Rousseff, do Partido dos Trabalhadores (PT), o livro deveria ser usado por alunos da rede pública de ensino durante três anos seguidos, de 2011 a 2013.

O "alvoroço" foi criado e sustentado por veículos midiáticos - redes de $\mathrm{TV}$, rádios, jornais impressos e online, e semanários - a partir de seis frases, extraídas da parte de Língua Portuguesa, cujo tema era variação linguística, sendo cinco delas descontextualizadas e uma frase criada pela primeira rede de televisão a divulgar a notícia - a Rede Globo. E, apesar de o livro estar de acordo com os Parâmetros Curriculares Nacionais (PCN) para a Língua Portuguesa, de 1997, e seguir as orientações curriculares do Conselho Nacional de Educação (CNE), os comentários eram de que o livro didático "continha erros" e "ensinava errado".

Embarcaram nessa patetice midiática não apenas renomados jornalistas, como Clóvis Rossi, Dora Kramer, Merval Pereira, dentre outros, como também alguns escritores, em seus próprios textos escritos ou em entrevistas, como Carlos Eduardo Novaes, Ana Maria Machado, Ruy Castro, José Sarney, Deonísio da Silva, dentre outros, o gramático Evanildo Bechara, e alguns educadores Cristóvão Buarque, Edgard Flexa Ribeiro, Sérgio Nogueira. A considerar seus textos e falas, nenhuma dessas personalidades públicas leu o capítulo do livro $^{3}$ para se manifestar: confiaram cegamente no que disse a Rede Globo no noticiário que foi o estopim para o alvoroço. Com a nossa pesquisa (MORARI, 2015), foi possível demonstrar que os jornalistas procuravam levar o leitor a acreditar que todo o conteúdo de Língua Portuguesa do livro

\footnotetext{
*Endereço eletrônico: eve_morari@yahoo.com.br

** Endereço eletrônico: clau.cmg@gmail.com
} 
didático estaria incorreto.

$\mathrm{Na}$ visão desses profissionais - que demonstram completa ignorância em relação ao campo de conhecimento da Linguística -, só vale a (suposta) língua portuguesa prevista nas regras de uso das gramáticas normativas. É "suposta", porque essa língua é imaginada, pois ela não dá conta de todas as possibilidades de uso do idioma, nem há um falante que faça uso de todas suas prescrições, ou nem mesmo de boa parte delas.

Diversos renomados linguistas entraram nesse "alvoroço midiático", e daí, sim, o alvoroço se configurou em "polêmica", ou pelo menos numa polarização em relação ao tema, pois passou a ser mostrado um outro ponto de vista em relação ao conteúdo do capítulo do livro, ao menos para os espectadores de TV, ouvintes de rádio ou leitores, não para os jornalistas, escritores, gramáticos e educadores, conforme mencionamos anteriormente, que se mantiveram em sua própria parvoíce. Todos eles foram arrogantes, pois não leram o capítulo do livro, que gerou a polêmica, e sobre o qual escreveram; confiaram cegamente no que foi apresentado em um programa de televisão da Rede Globo; não tiveram escuta para os argumentos de diversos linguistas, especialistas da linguagem, sobre o livro; e muito menos reconheceram todas as bobagens que eles próprios falaram e escreveram sobre a língua portuguesa e seu ensino, pois nenhum desses veículos midiáticos publicou um "erramos". Evidentemente que diante da ignorância de tantos assuntos, a maior parte dos profissionais (jornalistas, escritores etc.) contrários ao livro demonstrou também desconhecer a EJA, que, para diversos deles, é o antigo Mobral (Movimento Brasileiro de Alfabetização), criado no governo militar, e que vigorou de 1967 a 1985.

Não podemos deixar de registrar que houve escritores que, talvez mesmo sem terem lido o capítulo do livro gerador da polêmica, manifestaram-se tomando a língua/linguagem por uma perspectiva científica, mais precisamente por vertentes da Sociolingüística, como Affonso Romano de Sant'Anna, Cristóvão Tezza, Marcelino Freire, dentre outros. Assim como jornalistas que escreveram textos também nessa direção. Alguns deles foram: Eliane Brum, "O que 'os livro' contam?", Época, 23/05/2011; Maurício Dias, "Não existe apenas uma língua", Carta capital, 20/05/2011; Gabriel Perissé, "Entre o plural e a pluralidade", Observatório da Imprensa, 31/05/2011; Weden, "Jornalistas com deficit de letramento", Blog Luis Nassif Online, 28/05/2011.
Vale ainda não perdermos de vista que a mídia - TV, rádio, imprensa... - são empresas privadas, nas mãos de grandes e poderosos grupos econômicos ou famílias oligárquicas, com interesses comerciais e políticos, e estão longe de serem "imparciais" e "divulgarem apenas a verdade", como diversos veículos frequentemente afirmam em anúncios. Muito longe disso, servem a determinados grupos econômicos, grupos políticos, partidos políticos ou políticos individuais (MATTELART, 2002; ARBEX, 2001). Não é à toa que contemporaneamente é denominada de o Quarto Poder, depois dos Três Poderes - Legislativo, Judiciário e Executivo - em Estados democráticos. Nesse contexto, tudo o que chega até nós pela televisão, jornais impressos e online, rádio etc. é previamente selecionado por alguém, por grupos de pessoas, por empresas de comunicação. Aos telespectadores, leitores e ouvintes, só chega o que determinados grupos e empresas da área de Comunicação permitem divulgar. Em outras palavras, o mundo apresentado pelos meios midiáticos é editado para o público (BUCCI; KEHL, 2004). Com o advento da Internet e das redes sociais, esse quadro vem aos poucos se alterando, mas ainda assim a grande abrangência e capacidade dos meios midiáticos de formar opiniões sobre diversos temas continua bem forte.

Também não podemos perder de vista que ficou muito claro que toda essa agitação midiática foi criada como um meio de se fazer críticas aos governos do Partido dos Trabalhadores, tanto o da época, como o anterior, do Presidente Luiz Inácio Lula da Silva (2003-2010), e do Ministro da Educação na época, Fernando Haddad.

Posto isso para contextualizar o "alvoroço" em torno do livro, o que nos interessa neste artigo é analisar por uma abordagem discursivista as representações (imaginárias) do aluno da EJA, construídas por alguns desses jornalistas em nove textos, divulgados na grande imprensa impressa e online. A fim de contextualizar a polêmica em torno do livro, antes das representações construídas pelos jornalistas, apresentaremos as representações do aluno da EJA que emergem no livro Por uma vida melhor, construídas pela autora e editores do livro, e talvez por avaliadores do livro antes de ele ser publicado. Embora os jornalistas tratem do tema "língua/linguagem", em seus textos vazam as representações de alunos de escolas públicas de modo geral, já que a maior parte dos jornalistas demonstram desconhecer a EJA, e por extensão, de brasileiros de baixa renda, que atualmente é o 
público predominante das redes públicas de ensino.

Este artigo está organizado em duas seções, além desta "Introdução" e das "Considerações finais". Na seção seguinte, intitulada "O capítulo 'Escrever é diferente de falar' e a criação da polêmica pela mídia", apresentamos uma análise do capítulo do livro gerador da polêmica e, a partir dele, as representações do aluno da EJA, construídas pela autora do livro didático, bem como de possíveis avaliadores do livro antes de ele ter sido editado, assim como dos editores; apresentamos ainda as representações do aluno da EJA construídas pelos jornalistas. A seção posterior, "Representações do aluno da EJA construídas por jornalistas", é onde fazemos a análise dos textos jornalísticos, procurando identificar as representações do aluno, construídas por jornalistas. O referencial teórico será apresentado nessa seção, juntamente com a análise dos registros do corpus da pesquisa.

\section{O capítulo "Escrever é diferente de falar" e a criação da polêmica pela mídia}

Antes de tratarmos do livro, é importante fazermos algumas pontuações sobre a EJA.

Primeiramente, cabe esclarecer que a EJA comporta tanto cursos de alfabetização, como o Ensino Fundamental e Ensino Médio. Até 1988, ano da Nova Constituição do Brasil, a EJA estava voltada somente à alfabetização de adultos. Reafirmada na Lei de Diretrizes e Bases da Educação Nacional (LDBEN), de 1996, a EJA se ampliou até o Ensino Médio, como um direito à educação, e a partir de então o público passou a ser mais jovem. Assim, o programa que era voltado aos alunos analfabetos ou afastados da escola regular durante um longo tempo, atualmente recebe alunos jovens e que não estão há muito tempo afastados da escola, fazendo com que o foco da EJA seja outro (FÁVERO, 2011). O censo de 2000, por exemplo, indicava que EJA tinha aproximadamente 3 milhões de estudantes, sendo que desse total cerca de $79 \%$ deles eram jovens, o que caracteriza um novo perfil do aluno da EJA (BRUNEL, 2004).

Esse aumento no número de jovens migrando para a EJA está relacionado às mudanças na exigência da idade mínima para o ingresso à EJA, 15 anos para o Ensino Fundamental e 18 anos para o Ensino Médio, além das questões sociais que envolvem o aluno, muitas vezes desmotivado com a escola regular pelas seguidas repetências. Dois outros fatores que fazem com que os alunos migrem para a EJA são a duração dos cursos de dois anos para o Ensino Fundamental, $2^{\circ}$ Ciclo, e um ano e meio para o Ensino Médio, enquanto o ensino regular é de quatro e três anos, respectivamente, e o fato de a maior parte deles, que frequenta a EJA no período noturno, trabalhar durante o dia.

É importante esclarecer que os direitos autorais para autores de obras didáticas são de $6 \%$ sobre o preço de capa. Em compras governamentais, nem sempre os direitos autorais são pagos integralmente, podendo haver, inclusive, escalas progressivas de acordo com o número de exemplares comprados. Já quando um livro didático é adotado por escolas de redes privadas de ensino, ele é comprado em livrarias pelo preço estabelecido pela editora e o autor recebe os $6 \%$ de direitos autorais sobre o preço de cada livro vendido.

Os estudantes da EJA são oriundos predominantemente das camadas econômico-sociais mais baixas, estudam nas redes públicas de ensino e necessitam do material escolar distribuído pelo Ministério da Educação (MEC). Juntando esse fato ao que foi exposto acima sobre o pagamento dos direitos autorais, não é difícil pressupor que haja poucos profissionais que se dedicam à produção de obras didáticas - cujas vendas podem render grandes somas aos autores - interessarem-se em escrever obras didáticas para estudantes mais pobres e em número menor de classes, como não poderia deixar de ser.

Posto isso, voltemos ao livro.

O livro didático Por uma vida melhor, da coleção "Viver, Aprender", da editora Global, é multidisciplinar, destinado ao $2^{\circ}$ Ciclo do Ensino Fundamental da EJA, que equivale ao período do $6^{\circ}$ ao $9^{\circ}$ ano do Ensino Fundamental regular. Ele foi aprovado pelo PNLD para ser utilizado nos anos letivos de 2011 a 2013.

Ainda que de forma breve, vale esclarecer como se dá a escolha de livros pelo PNLD. A Secretaria de Educação Básica do MEC convida universidades públicas de notório saber na análise de livros didáticos, em cada área do conhecimento. Cabe a elas organizar equipes de pareceristas, formadas por docentes da educação básica, com qualificação mínima de mestrado, e professores e pesquisadores universitários, com comprovada experiência acadêmica, didática e pedagógica. Cada obra é avaliada por pelo menos dois pareceristas; caso não haja consenso, ela é submetida a um terceiro. Dependendo dos temas tratados e das especialidades envolvidas, o mesmo livro é submetido a outros pareceristas especialistas em 
outras áreas do conhecimento. ${ }^{2}$

O livro Por uma vida melhor é composto por 6 unidades, que correspondem às disciplinas de Língua Portuguesa, Língua Inglesa, Arte e Literatura, Matemática, Ciências Humanas: História e Geografia e Ciências Naturais, sendo que cada uma das disciplinas é organizada por capítulos e por diferentes autores, 14 no total: Carolina Amaral de Aguiar, Claudio Bazzoni, Denise Grispum, Denise Mendes, Dulce Satiko Onaga, Fábio Fernandes Madeira Lourenço, Helena Henry Meirelles, Heloisa Ramos, José Carlos Fernandes Rodrigues, Maria Amábile Mansutti, Marina Marcos Valadão, Mirela Laruccia Cleto, Noemi Jaffe e Roberto Giansanti. Não está discriminado no livro quais autores se responsabilizam por quais partes; no entanto, a parte de Língua Portuguesa é atribuída a Heloisa Ramos. Com 288 páginas, 62 delas são para Língua Portuguesa, parte que é composta por quatro capítulos: 1) Escrever é diferente de falar (17 páginas); 2) Histórias, histórias, histórias... (17 páginas); 3) Texto de divulgação científica (14 páginas); 4) A hora e vez do leitor (14 páginas).

O gerador do alvoroço midiático foi $\mathrm{o}$ primeiro capítulo, "Escrever é diferente de falar", onde são apresentados os conteúdos: variação linguística, regras de acentuação, concordância verbal e nominal, emprego de pronomes e formação de parágrafos (AGUIAR, 2009, p. 15) . $^{3}$

Toda a parte de Língua Portuguesa está baseada na abordagem da Linguística Estrutural para ensino/aprendizagem de línguas, que consiste na repetição de "modelos", como, por exemplo:

Leia o modelo e, a seguir, complete as frases.

É preciso estudar as regras.

É preciso estudá-las.

a) Eu gostaria de admirar o país.

Eu gostaria de.

[...] (AGUIAR, 2009, p. 26).

A maior parte do conteúdo de Língua Portuguesa é composta por exposição de regras gramaticais, com o emprego da Nomenclatura Gramatical, seguida de explicações breves e superficiais, muitas vezes. O estudo de textos dá-se por meio de perguntas, cujas respostas esperadas seriam facilmente localizáveis no próprio texto; são perguntas que não levam o aluno a refletir sobre o texto para responder.

De forma geral, as explicações sobre o conteúdo gramatical oscilam entre a brevidade e a superficialidade, quando não as duas características: breve e superficial. Isso vale também para os conteúdos que não gramaticais, como, por exemplo, com o conceito de "eu lírico" para o qual não há definição ou qualquer explicação; a autora apenas se reporta a ele nas perguntas de interpretação de texto (AGUIAR, 2009, p. 22).

A parte que trata das "variantes linguísticas" não é diferente. A autora informa ao aluno que a Língua Portuguesa tem diversas variantes linguísticas, sendo a norma padrão uma delas, embora não diga isso explicitamente. No entanto, a autora não apresenta a definição de "variante linguística", nem mesmo uma explicação por meio da qual o aluno possa chegar à definição. A explicação dada é confusa, pois para se referir a variante(s) linguística(s) ela emprega sete diferentes termos, sem nenhuma definição: "formas linguísticas", "norma culta", "norma popular", "variedade popular", "padrão de correção", "padrão da norma culta" e "variante adequada" (AGUIAR, 2009, p. 14). Ocorre algo semelhante para a noção de "preconceito linguístico", que não é definido, nem é apresentada explicação por meio da qual o aluno possa chegar à definição; a autora se vale da oposição "pode"/“não pode".

Até mesmo para a redação, quando o aluno poderia criar mais livremente um texto autêntico, dele próprio, a proposta é dirigida. Vejamos como a produção escrita é conduzida, na seção do livro intitulada "Momento da escrita":

Leia o início do parágrafo a seguir e copie-o no caderno. Identifique o assunto tratado e continue a escrevê-lo. Use as palavras que estão abaixo (mas, além disso, assim) observando o sentido de cada uma para iniciar os parágrafos seguintes. No final, crie um título para o texto.

A voz da mulher é ainda pouco ouvida em nossa sociedade. Afinal, ter competência para falar não implica ser ouvido.

Mas...

Além disso...

Assim... (AGUIAR, 2009, p. 27).

Em geral, os exercícios e a proposta de redação não levam em conta as características da escrita dos alunos, nem o estilo de escrita de cada um. O que esse tipo de exercício faz é submeter o aluno a uma série de repetições, seguindo instruções de uso. Assim, o livro parece trazer o conteúdo sobre variantes linguísticas apenas para cumprir uma exigência dos PCN, pois os exercícios e a proposta de redação são conduzidos de maneira tradicional e recaem no método estruturalista de ensino de línguas. Parece-nos haver, aqui, uma 
contradição entre o tema do capítulo, "variação linguística", conteúdo que, em princípio, ampliaria a visão do aluno sobre língua/linguagem, e o tratamento dado ao tema e ao conteúdo gramatical, ambos de base estruturalista.

A representação de aluno que o livro didático transmite é a de alguém que precisa ser direcionado para qualquer atividade com a língua portuguesa, sua língua materna, seja em exercícios de linguagem, seja na leitura e interpretação de textos e até mesmo na produção escrita. Seria aquele aluno que precisaria de tutela para aprender determinados conteúdos, de certa forma inábil para conduzir seu próprio aprendizado.

Antes de passarmos para a polêmica criada pela mídia, destacamos que, apesar das deficiências do livro, conforme apontamos anteriormente, ele

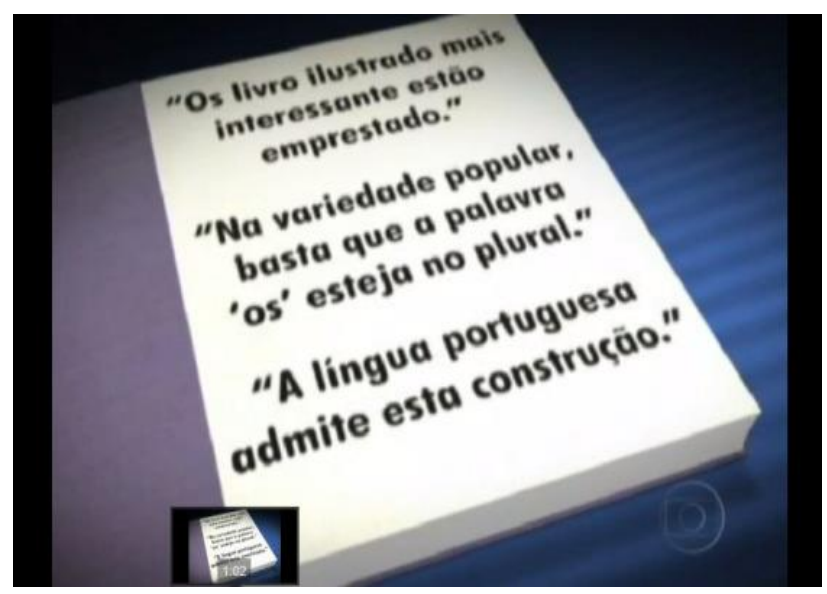

No quadro a seguir, apresentamos a reprodução do conteúdo da página 14 do livro Por uma vida melhor de onde foi extraído o conteúdo não apresenta erros gramaticais na unidade Língua Portuguesa.

Passemos à polêmica midiática.

A primeira notícia sobre o livro didático "contendo erros", para usar termos empregados pelos diversos veículos midiáticos, foi divulgada no programa Bom Dia Brasil, da Rede Globo, em 17 de maio de 2011, quando circularam as imagens descontextualizadas de um livro com apenas seis frases, sendo cinco delas extraídas do livro e uma inventada pelos jornalistas, as quais representariam o livro didático Por uma vida melhor. Evidentemente que tal notícia veiculou no programa Jornal Nacional, cuja audiência é ainda maior, do mesmo dia, também da Rede Globo, exibido em torno de 20 horas. Abaixo seguem as duas imagens com as seis frases, exibidas nos programas:

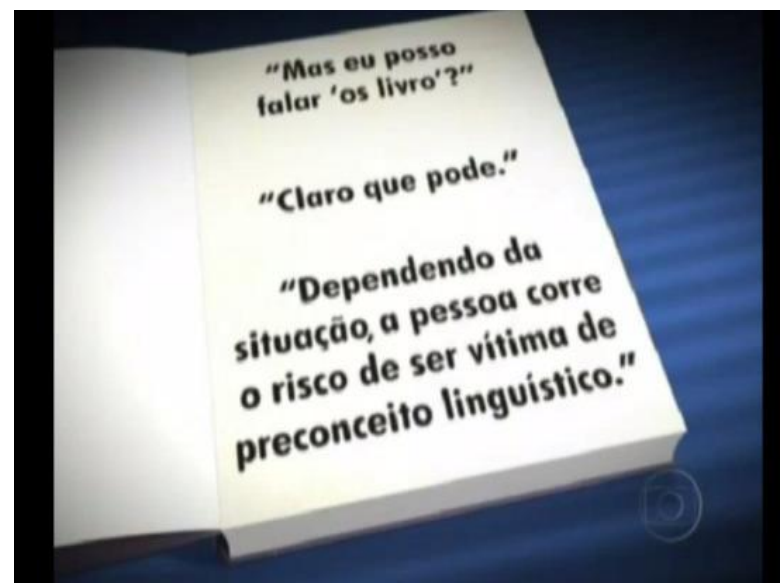

exibido pela Rede Globo. Os negritos constam da página do livro. 


\section{A concordância entre as palavras}

\section{p. 14}

A concordância entre as palavras é uma importante característica da linguagem escrita e oral. Ela é um dos princípios que ajudam na elaboração de orações com significado, porque mostra a relação existente entre as palavras.

Verifique como isso funciona:

Alguns insetos provocam doenças, às vezes, fatais à população ribeirinha.

insetos (masculino, plural) $\leftarrow$ alguns (masculino, plural)

doenças (feminino, plural) $\leftarrow$ fatais (feminino, plural)

população (feminino, singular) $\leftarrow$ ribeirinha (feminino, singular)

As palavras centrais (insetos, doenças, população) são acompanhadas por outras que esclarecem algo sobre elas. As palavras acompanhantes são escritas no mesmo gênero (masculino/feminino) e no mesmo número (singular/plural) que as palavras centrais.

Essa relação ocorre na norma culta. Muitas vezes, na norma popular, a concordância acontece de maneira diferente. Veja:

Os livro ilustrado mais interessante estão emprestado.

$$
\begin{aligned}
\text { livro (masculino, singular) } \rightarrow & \text { os (masculino, plural) } \\
& \text { ilustrado (masculino, singular) } \\
& \text { interessante (masculino, singular) } \\
& \text { emprestado (masculino, singular) }
\end{aligned}
$$

Você acha que o autor dessa frase se refere a um livro ou a mais de um livro? Vejamos:

$\mathrm{O}$ fato de haver a palavra os (plural) indica que se trata de mais de um livro. Na variedade popular, basta que esse primeiro termo esteja no plural para indicar mais de um referente. Reescrevendo a frase no padrão da norma culta, teremos:

Os livros ilustrados mais interessantes estão emprestados.

Você pode estar se perguntando: "Mas eu posso falar 'os livro?'."

Claro que pode. Mas fique atento porque, dependendo da situação, você corre o risco de ser vítima de preconceito linguístico. Muita gente diz o que se deve e o que não se deve falar e escrever, tomando as regras estabelecidas para a norma culta como padrão de correção de todas as formas linguísticas. $\mathrm{O}$ falante, portanto, tem de ser capaz de usar a variante adequada da língua para cada ocasião.

Note que na primeira cena exibida pelo telejornal da Rede Globo, a frase "A língua portuguesa admite esta construção" foi inventada, pois ela não consta no livro. Além de eliminar toda a explicação em torno da frase "Os livro ilustrado mais interessante estão emprestado.”, na segunda cena há a eliminação do início da oração adversativa, "Mas fique atento porque", e a troca do pronome pessoal "você" por "a pessoa", modificações que podem levar o telespectador à produção de sentido de que o aluno "poderia tudo" em relação à língua. A parte inicial excluída da oração adversativa, no livro, serve como um alerta ao aluno de que não é aconselhável a utilização da norma popular em todas as situações e, em seguida, há a explicação da autora para a concordância nominal, conforme a norma padrão da língua portuguesa.

\section{Representações do aluno da EJA construídas por jornalistas}


Os textos selecionados para a constituição do corpus foram os nove seguintes, expostos com os respectivos veículos de imprensa, em ordem alfabética:

1) O Estado de S. Paulo, 17/05/2011 - Dora Kramer, "Por uma vida pior".

2) Folha de S. Paulo, 15/05/2011 - Clóvis Rossi, "Inguinorança".

3) O Globo, 17/05/2011 - Merval Pereira, "Visão perversa".

4) iG São Paulo, 19/05/2011 - Tatiana Klix, "Entenda a polêmica do livro que defende o "nós pega" na escola.

5) iG São Paulo, 12/05/2011 - Clarissa Oliveira, "Livro usado pelo MEC ensina aluno a falar errado".

6) Istó́, 20/05/2011 - Amauri Segalla e Bruna Cavalcanti, "O assassinato da língua portuguesa".

7) IstoÉ, 20/05/2011 - Carlos José Marques, “A consagração da ignorância".

8) Jornal do Brasil, 16/05/2011 - Carlos Eduardo Novaes, "Livros pra inguinorantes".

9) Veja, 23/05/2011 - Renata Betti e Roberta de Abreu Lima, "Os adversários do bom português".

Nas sequências discursivas apresentadas a seguir, é possível perceber diversas outras representações construídas por jornalistas também muito ricas na produção de efeitos de sentido, tais como as de línguas, e especificamente de língua portuguesa, de ensino de língua, da autora do livro, de professor, representações estas que foram analisadas no estudo de Morari (2015). Outras representações igualmente ricas na produção de efeitos de sentido são as construídas para a Linguística, os linguistas e o governo da época, do PT. No entanto, dado o objetivo deste artigo, analisaremos apenas as representações do aluno da EJA construídas por jornalistas.

Nos textos, fica claro que os jornalistas não sabem do que trata a EJA. O que eles parecem saber é que o livro se destina para estudantes de redes públicas de ensino (estaduais e municipais), já que fazem parte da compra pelo PNLD, e, sendo alunos da rede pública, em sua maioria são de baixa renda. A partir disso, as representações construídas para o aluno da rede pública são também as mesmas três grandes representações para os pobres que circulam no Brasil: o pobre é pobre porque ou é "preguiçoso", ou "desafortunado", ou "burro".

Selecionamos uma série de oito sequências discursivas, de oito jornalistas, as quais apresentam regularidades enunciativas, o que as colocam em um mesmo discurso.

Antes de passarmos a elas, cabe a definição de discurso de que nos valemos para a seleção e análise dos registros do corpus. Numa abordagem discursivista, um discurso realiza-se na materialidade linguística como um conjunto de enunciados que se apóia num conjunto de regras, as formações discursivas, que, por sua vez, materializam determinadas ideologias. Esse conjunto de regras está em constante movimento, produzindo, sempre, novos saberes, fazendo com que determinados sentidos permaneçam presentes com o passar do tempo e outros sejam esquecidos, podendo voltar a ser enunciados em algum outro momento histórico (FOUCAULT, [1969]1987; [1970]1996a). Dessa forma, entende-se o discurso como algo que não é exclusivamente a linguagem, mas é por meio dela que ele existe e, nesta perspectiva, a linguagem funciona como uma mediação entre $\mathrm{o}$ sujeito $\mathrm{e}$ a realidade, possibilitando deslocamentos tanto no sujeito quanto na realidade em que ele vive.

Antes de passarmos para a análise das sequências, é importante trazermos, aqui, a noção de "sujeito", que na abordagem teórica na qual nos ancoramos ele se constitui por meio da linguagem de outros sujeitos, que materializam discursos diversos. O sujeito é resultante de várias vozes, as quais revelam o seu lugar social, histórico e ideológico, fazendo dele um sujeito essencialmente ideológico e histórico, pois se insere em um tempo e espaço social, tempo e espaço de onde fala, o que o define, embora tenha a ilusão de ser fonte do seu dizer (PÊCHEUX, [1969]1990; [1975]1988). Essa ilusão do sujeito de constituir-se em indivíduo autônomo é o que Foucault ([1979]1996b) denomina de "produto do exercício de poder".

O sujeito aqui tratado é atravessado pela ideologia e pelo inconsciente, fazendo com que ele não seja uno, mas sim um sujeito que não se constitui como fonte do seu dizer. A ilusão do sujeito de ser fonte do seu dizer é um efeito da ideologia, que funciona por meio das relações de forças de uma sociedade. Desse modo, o sujeito é um indivíduo constituído pelo inconsciente, interpelado pela ideologia, inserido em uma formação discursiva que delimita o seu dizer. Dessa forma, os sujeitos se identificam com a ideologia de um determinado grupo, sem se dar conta. Por esse motivo e também porque é constituído pelo inconsciente, o sujeito é descentrado (PÊCHEUX, [1969]1990; [1975]1988). 
É a partir dessa noção de "sujeito" que entendemos os discursos materializados pelos dizeres da autora do livro no livro, dos dizeres dos jornalistas materializados em seus textos.

Passemos, então, para as sequências discursivas, as quais ao tratarem do aluno o tomam como aquele que não domina - nem mesmo saberia que existe -, a norma padrão da língua. O parâmetro para os jornalistas são as regras de uso da língua abonadas pelas gramáticas normativas, ou melhor, o que eles entendem como sendo as regras das gramáticas normativas. Evidentemente que essa posição enunciativa em relação à língua é resultado de suas filiações ideológicas enquanto sujeitos, por isso materializam em seus dizeres certos discursos, e não outros. E é nesses discursos que emergem as representações para o aluno da EJA.

(1) Em vez de manter o jovem que não domina a língua imerso na triste ignorância - a pretexto de preservar suas raízes culturais - por que não retirá-lo de lá? (Amauri Segalla e Bruna Cavalcanti, "O assassinato da língua portuguesa", IstoÉ, 20/05/2011).

(2) Certamente um desserviço aos jovens de uma nação de iletrados sedenta de conhecimentos (Renata Betti e Roberta de Abreu Lima, "Os adversários do bom português", Veja, 23/05/2011).

(3) Com o selo oficial do MEC, a obra agride normas gramaticais e estabelece um novo padrão de pedagogia em que a leniência e o descaso com o ensino viram praxe. Com essa rendição na formação do brasileiro o País pode entrar numa rota perigosa rumo ao atraso e à delinquência educacional. "Por uma Vida Melhor" indica ainda que, no mundo do "politicamente correto", orientar o aluno para que ele empregue o idioma na sua forma certa equivale a um "preconceito linguístico". Não cabem parâmetros ou regras convencionais. $\mathrm{O}$ uso impróprio é aceitável. A banalização do português é permitida.

[...]

Professores ganham mal, logo não se pode exigir deles que tirem alunos do estado de ignorância! Deforma-se assim o caráter do brasileiro. (Carlos José Marques, "A consagração da ignorância”, IstoÉ, 20/05/2011)

(4) Apesar da polêmica, o Ministério da Educação não pretende proibir o livro. Depois de divulgar nota em que afirma que papel da escola não é só o de ensinar a forma culta da língua, mas também $o$ de combate ao preconceito contra os alunos que falam "errado", o próprio ministro Fernando Haddad afirmou que não tem motivos para censurar a obra. (Tatiana Klix, "Entenda a polêmica do livro que defende o "nós pega" na escola, $i G$ São Paulo, 19/05/2011)

(5) Livro didático de língua portuguesa adotado pelo MEC (Ministério da Educação) ensina aluno do ensino fundamental a usar a "norma popular da língua portuguesa".

$\mathrm{O}$ volume Por uma vida melhor, da coleção Viver, aprender, mostra ao aluno que não há necessidade de se seguir a norma culta para a regra da concordância. Os autores usam a frase "os livro ilustrado mais interessante estão emprestado" para exemplificar que, na variedade popular, só "o fato de haver a palavra os (plural) já indica que se trata de mais de um livro". Em um outro exemplo, os autores mostram que não há nenhum problema em se falar "nós pega o peixe" ou "os menino pega o peixe". (Clarissa Oliveira, "Livro usado pelo MEC ensina aluno a falar errado", iG São Paulo, 12/05/2011)

(6) [...] é muito mais difícil ensinar o certo do que aceitar o errado com o qual o aluno chega à escola.

[...]

Tal como matar alguém viola uma norma, matar o idioma viola outra. Condenar uma e outra violação está longe de ser preconceito. É um critério civilizatório. (Clóvis Rossi, "Inguinorança", Folha de S. Paulo, 15/05/2011).

(7) Fica, portanto, estabelecido que o ministério [da Educação] encarregado dos assuntos educacionais no Brasil, além de desmoralizar os mecanismos de avaliação de desempenho escolar, não vê problemas em transmitir aos alunos o conceito de que as regras gramaticais são irrelevantes. (Dora Kramer, "Por uma vida pior”, O Estado de S. Paulo, 17/05/2011)

(8) Enquanto distorções políticas que afetem posições pessoais do aluno podem ser revertidas no decorrer de sua vida, por outros conhecimentos e vivências, distorções didáticas afetam a perspectiva desse aluno, que permanecerá analfabeto, sem condições de melhorar de vida.

[...]

$\mathrm{Na}$ verdade, está é agravando as condições precárias do cidadão-aluno que busca na escola melhorar de vida, limitando, se não impossibilitando, que atinjam esse objetivo. (Merval Pereira, "Visão Perversa", O Globo, 17/05/2011). 
Nessa série de sequências discursivas, as representações do aluno da EJA são todas desqualificadoras por insistirem em rebaixá-lo com o emprego dos seguintes termos ou expressões: "o jovem que não domina a língua", "o ignorante", o "iletrado", "o que fala errado", "o desgraçado", "o analfabeto". Vejamos em detalhe cada uma das sequências.

Em (1), os termos "jovem que não domina a língua imerso na triste ignorância" equivale à "ignorante", onde "ignorância" em relação à norma padrão da língua é posta como sendo "triste"; o dêitico "lá" se refere tanto à "triste ignorância", como também às "raízes culturais" do aluno, pressupondo que sua cultura é inferior à cultura da qual fazem parte os dois jornalistas, autores do texto, já que eles sugerem retirar o aluno de "suas raízes culturais". Em (2), com o trecho "jovens de uma nação de iletrados", a representação para o aluno da EJA é de "iletrado". Em (3), a representação do aluno construída pelo jornalista é de "ignorante", já que ele estaria num "estado de ignorância", por não empregar a língua padrão, o que o leva "à delinquência educacional", portanto, "um delinquente educacional". Curiosamente, nessa sequência, o jornalista modifica o sentido de "preconceito linguístico", pois este não seria dos que (supostamente) empregam a língua padrão em relação aos que não a empregam; o jornalista entende que a autora do livro recomenda ao aluno de escola pública que empregue a norma padrão, como uma das maneiras de ser "politicamente correto", a fim de evitar o "preconceito linguístico". $\mathrm{Na}$ sequência (4), embora a jornalista grafe a palavra "errado" entre aspas, o que aparentemente parece abonar a (suposta) linguagem dos alunos, a frase que antecede a frase com a palavra aspeada, no entanto, confirma justamente o contrário: que o aluno "fala errado", não sabe a "forma culta da língua". Na sequência (5), a referência ao aluno se dá por meio da ironia, criada com as aspas (e o itálico nosso) no trecho: "Livro didático de língua portuguesa adotado pelo MEC (Ministério da Educação) ensina aluno do ensino fundamental a usar a "norma popular da língua portuguesa", afirmando que o livro ensinaria a "norma popular". Essa afirmação, no entanto, serve para negar, pois está subentendido que não é preciso ensinar o que o aluno já sabe. Com essa construção de linguagem, em que se afirma algo para negá-lo, se dá a ironia. A representação do aluno que emerge dessa sequência é daquele que fala a "norma popular da língua", que na visão da jornalista não sabe a norma culta. Em (6), o aluno seria aquele que "fala errado", um "inguinorante", conforme o título do texto; conhecer a norma padrão da língua e saber usá-la faria do aluno, segundo o jornalista, um "ser civilizado", afirmação da qual se pode deduzir o contrário: quem não conhece a norma padrão da língua e, portanto, não a emprega não seria civilizado. Ainda em (6), o título do texto, "Inguinorança", procura reproduzir a suposta maneira de falar a palavra "ignorância" por pessoas pouco, ou nada, escolarizadas, o que inferioriza o suposto aluno, parte do público-alvo do livro. Na sequência (7), a representação do aluno seria a de "desgraçado" não pelo que está dito no texto, mas pelo título que faz um trocadilho com o do livro, "Por uma vida pior", o que já pressupõe que a vida do aluno não é das melhores. E em (8), o aluno é tomado como "analfabeto" e, dadas as "distorções didáticas" do livro, assim permanecerá. Nessa última sequência, como os demais jornalistas, Merval Pereira ignora que o livro didático é destinado para o $2^{\circ}$ Ciclo do Ensino Fundamental da EJA, ou seja, os alunos já estão alfabetizados.

Em todas essas sequências as representações do aluno da EJA que emergem são de que ele: tem raízes culturais inferiores às dos jornalistas (sequência 1); é iletrado (2) e analfabeto (8); é dependente de um professor-salvador que o oriente e que o tire do "estado de ignorância" (3); é vítima de preconceito por falar errado (4); acredita e absorve tudo que lê (5) ou tudo que o professor supõe transmitir (7); fala errado, é ignorante e não civilizado (6). Em outras palavras, as representações do aluno da EJA, construídas pelos jornalistas sem que saibam do que se trata a EJA, mas considerando que sabem que o livro é destinado para alunos de escolas públicas e de baixa renda, são: de uma pessoa que fala errado, é ignorante, analfabeta, passiva para absorver o conhecimento que pode lhe ser transmitido e incapaz de refletir sobre um determinado tema e chegar à determinada conclusão.

Ao construir essas representações para o aluno, os jornalistas se colocam acima de todas elas. Eles seriam os que falam e escrevem conforme a norma padrão da língua portuguesa (segundo eles, conforme a única língua portuguesa que há), seriam críticos e questionadores e, evidentemente, não seriam ignorantes - em nenhum assunto. No entanto, não foi difícil localizar em seus textos, apenas nos recortes discursivos que selecionamos, construções em desacordo com a norma padrão da língua portuguesa, ou emprego inadequado de 
termos na oração, bem como construções, embora compreensíveis, com sintaxe estranha à língua portuguesa. Em (1), "triste ignorância" e "retirá-lo [o aluno] de suas raízes culturais" - não se tem ignorância que seja triste ou alegre e não se trata de retirar alguém de suas raízes culturais, mas retirar estas (raízes culturais) de alguém, ainda que isso seja imoral, ou da ordem do impossível. Na sequência (2), parece-nos contraditório dizer "uma nação de iletrados sedenta de conhecimentos". Em (3), o jornalista inverte o que seria "preconceito linguístico", como analisamos anteriormente. Em (4), faltam o emprego do artigo definido e paralelismo sintático nos trechos que assinalamos em itálico, entre colchetes: "Depois de divulgar nota em que afirma que [o] papel da escola não é só o de ensinar a forma culta da língua, mas também o de combate ao [combater o] preconceito contra os alunos que falam "errado"[...]". Em (5), o trecho a seguir ficaria melhor com a correção do que está pusemos em itálico, entre colchetes: "só 'o fato de haver a palavra os (plural) já indica [há indicação de] que se trata de mais de um livro"”. Em (6), o melhor termo seria "lei" em vez de "norma" no trecho: "como matar alguém viola uma norma". Em (7), os termos "o conceito de" é desnecessário no trecho: "não vê problemas em transmitir aos alunos $o$ conceito de que as regras gramaticais são irrelevantes". Na sequência (8), há um erro de concordância no trecho a seguir, que assinalamos em itálico, entre colchetes: "está é agravando as condições precárias do cidadão-aluno [termo no singular] que busca na escola melhorar de vida, limitando, se não impossibilitando, que atinjam [termo no plural] esse objetivo."

Vale lembrar que em todo o capítulo do livro didático que gerou a polêmica é insistentemente recomendado que $\mathrm{o}$ aluno apre(e)nda e empregue as formas da norma padrão da língua portuguesa. Aliás, além de a autora fazer isso em todo o capítulo do livro, parece se sentir desconfortável ao incluir o conteúdo das variantes linguísticas, como vimos anteriormente, uma vez que inclui tal conteúdo de maneira breve e superficial.

Para finalizar a análise, apresentamos uma sequência discursiva extraída de um texto cujo autor é um escritor, Carlos Eduardo Novaes. Selecionamos seu texto, porque Novaes também escreve regularmente para jornais e porque, a nosso ver, é ofensiva e desrespeitosa sua posição em relação ao aluno da EJA e por extensão aos brasileiros mais pobres, sobretudo porque ele é escritor, não um mero jornalista, que, muitas vezes, é pago para defender determinadas ideias.

(9) Eu dou um duro danado para não tropesssar na Gramática e nunca tive nenhum dos meus 42 livros comprados pelo Pograma Naçional do Livro Didáctico. Vai ver que é por isso: escrevo para quem sabe Português! (Carlos Eduardo Novaes, "Livros pra inguinorantes", Jornal do Brasil, 16/05/2011).

Ao se reportar aos seus 42 livros, Novaes vale-se da ortografia correta, diferentemente do que é feito antes e depois dessas frases: "nunca tive nenhum dos meus 42 livros comprados" e "Vai ver que é por isso: escrevo para quem sabe Português!" $\mathrm{O}$ resto da sequência, assim como a maior parte do seu texto, é escrita com ortografia incorreta, procurando imitar a suposta escrita de uma pessoa pouco escolarizada. Nessa sequência, tal como as de Rossi (sequência 6) e Kramer (7), o título contribui para a produção dos efeitos de sentido: "Livros pra inguinorantes". De maneira semelhante à de Rossi (6), a palavra "ignorante" é registrada com a suposta maneira de falar de uma pessoa com baixa ou nenhuma escolarização. Na lógica do escritor, por ele escrever "para quem sabe Português!", nunca teve seus livros adquiridos pelo PNLD, afirmando, assim, que os alunos do EJA não saberiam português, público-alvo do livro didático. Com isso, Novaes se coloca acima do aluno da EJA, ao mesmo tempo em que para este constrói representações de "pessoa ignorante" e "que não sabe português, nem para falar, nem para escrever".

Em Ghiraldelo (2002), pudemos constatar que a língua/linguagem de um indivíduo é o elemento de sua identidade pessoal que mais desperta a atenção do outro, em muitos casos, antes mesmo de sua aparência física. Ao falar, o indivíduo já revela diversas características de sua constituição como sujeito, de sua história de vida.

\section{Considerações finais}

Se os jornalistas erraram a mão com os textos que produziram sobre o livro Por uma vida melhor, a autora do livro também errou. Não por desqualificar o aluno da EJA - como fazem os jornalistas, ainda que não saibam o que é a EJA -, mas por não considerá-lo capaz de atingir autonomia para seu próprio aprendizado. Com a análise do capítulo do livro, o que gerou a polêmica, pudemos verificar que a forma como o conteúdo de variação linguística é abordado se dá de maneira 
incompleta, superficial e confusa, pois não há muitas explicações, além de serem utilizados termos específicos da Linguística, especificamente da Sociolingüística, sem as respectivas definições. Além disso, os exercícios propostos, a interpretação de texto e a proposta de escrita são fundamentados na Linguística estrutural, o que restringe o tratamento da linguagem, pois submete o aluno a uma série de repetições a partir de instruções, ou modelos, de emprego de formas da língua. O conteúdo sobre variação linguística parece-nos constar do livro apenas para cumprir uma exigência dos PCN.

A análise das representações do aluno da EJA, construídas por jornalistas é de que seria "analfabeto", "iletrado", "ignorante", "delinquente educacional", "que fala errado", "que não sabe a língua"... e, assim, permanecerá, representações estas que se estendem para os alunos das redes públicas de ensino e, consequentemente, estendemse também para as pessoas mais pobres, pois hoje, no Brasil, a rede de ensino regular pública atende quase exclusivamente os mais pobres. Com a análise das sequências discursivas extraídas dos discursos materializados nos textos jornalísticos, podemos afirmar que, para escreverem seus textos, os jornalistas se pautaram exclusivamente na notícia da Rede Globo, não leram o capítulo do livro e ignoram o que é a EJA.

\section{Notas}

1 Agradecemos à FAPESP pelo apoio financeiro para o desenvolvimento desta pesquisa (processo 2013/23427-0), que resultou na Dissertação de Mestrado de MORARI (2015), cf. referência a seguir.

2 Disponível em: <www.portal.mec.gov.br> Acesso: 08/01/2015.

3 A parte de Língua Portuguesa é atribuída a Heloisa Ramos, o primeiro autor do livro didático é Carolina Amaral de Aguiar, por isso mantemos a referência como AGUIAR (2009).

\section{Referências}

AGUIAR, C. A. et al. Por uma vida melhor. Coleção "Viver, Aprender". Volume 2 / multidisciplinar. São Paulo: Editora Global, 2009.

\section{ARBEX, J. Showrnalismo a notícia como}

espetáculo. 2. ed. São Paulo: Casa Amarela, 2001.

BRUNEL, C. Jovens cada vez mais jovens na Educação de Jovens e Adultos. Porto Alegre: Mediação, 2004.

BUCCI, E.; KEHL, M. R. (Orgs.). Videologias. São Paulo: Boitempo, 2004.

FÁVERO, O. Políticas públicas de Educação de Jovens e Adultos no Brasil. In: SALES, S. R.; SOUZA, J. dos S. (Org.). Educação de Jovens e Adultos: políticas e práticas educativas. Rio de Janeiro: NAU Editora / EDUR, 2011. p. 29-46.

FOUCAULT, M. (1969). A arqueologia do saber. Tradução Luiz Felipe Baeta Neves. Rio de Janeiro: Forense Universitária, 1987.

(1970). A ordem do discurso. Tradução

Laura Fraga de Almeida Sampaio. São Paulo: Edições Loyola, 1996a.

(1979). Microfísica do poder. Tradução e organização Roberto Machado. Rio de Janeiro: Edições Graal, 1996b.

GHIRALDELO, C. M. As representações de língua materna: entre o desejo de completude e a falta do sujeito. 2002. $239 \mathrm{f}$. Tese (Doutorado em Linguística Aplicada) - Universidade Estadual de Campinas, Campinas, SP, 2002.

MATTELART, A. A globalização da comunicação. Tradução Laureano Pelegrin. Bauru, SP: EDUSC, 2002.

MORARI, E. R. Representações de Língua Portuguesa construídas pela imprensa: estudo da polêmica em torno do livro didático Por uma vida melhor. 2015. 135 f. Dissertação (Mestrado em Linguística Aplicada) - Universidade de Taubaté, Taubaté, SP, 2015.

PÊCHEUX, M. (1969). Análise automática do discurso (AAD-69). In: GADET, F.; HAK, T. (Orgs.). Por uma análise automática do discurso. Uma introdução à obra de Michel Pêcheux. Tradução Bethania S. Mariani et al. Campinas, SP, Editora Unicamp, 1990.

(1975). Semântica e discurso: uma crítica à afirmação do óbvio. Tradução Eni Pulcinelli Orlandi et al. Campinas, SP:Editora Unicamp, 1988. 


\section{Sobre as autoras}

Evelise Raquel Morari é Professora de Língua Portuguesa e Língua Inglesa, graduada pela Universidade Estadual do Centro-Oeste (UNICENTRO), SC, e mestre em Linguística Aplicada pela Universidade de Taubaté (UNITAU).

Claudete Moreno Ghiraldelo é Professora na pós-graduação em Linguística Aplicada da UNITAU, fez pósdoutorado no Centro de Estudos Sociais da Universidade de Coimbra e tem formação em Psicanálise pelo CLINa da Escola Brasileira de Psicanálise, SP.

Recebido em agosto de 2016.

Aprovado em outubro de 2016. 